\title{
Molecular regulation of fruit ripening
}

\author{
Sonia Osorio ${ }^{1,2}{ }^{*}$, Federico Scossa ${ }^{1,3}$ and Alisdair R. Fernie ${ }^{1}$ \\ ${ }^{1}$ Max-Planck-Institut für Molekulare Pflanzenphysiologie, Potsdam-Golm, Germany \\ ${ }^{2}$ Departamento de Biología Molecular y Bioquímica, Instituto de Hortofruticultura Subtropical y Mediterránea "La Mayora," Consejo Superior de Investigaciones \\ Científicas, Universidad de Málaga, Málaga, Spain \\ ${ }^{3}$ Consiglio per la ricerca e la sperimentazione in agricoltura, Centro di ricerca per I'Orticoltura, Pontecagnano (Salerno), Italy
}

\section{Edited by:}

Malcolm Bennett, The University of Nottingham, UK

\section{Reviewed by:}

James Giovannoni, Cornell University, USA

Graham Seymour, University of Nottingham, UK

Carol Wagstaff, University of Reading, UK

\section{${ }^{*}$ Correspondence:}

Sonia Osorio, Departamento de Biología Molecular y Bioquímica Instituto de Hortofruticultura Subtropical y Mediterránea "La Mayora," Consejo Superior de Investigaciones Científicas, Universidad de Málaga, Edificio $1+D$ $3^{a}$ Planta, Campus Teatinos, 29071 Málaga, Spain

e-mail: sosorio@uma.es
Fruit ripening is a highly coordinated developmental process that coincides with seed maturation. The ripening process is regulated by thousands of genes that control progressive softening and/or lignification of pericarp layers, accumulation of sugars, acids, pigments, and release of volatiles. Key to crop improvement is a deeper understanding of the processes underlying fruit ripening. In tomato, mutations blocking the transition to ripe fruits have provided insights into the role of ethylene and its associated molecular networks involved in the control of ripening. However, the role of other plant hormones is still poorly understood. In this review, we describe how plant hormones, transcription factors, and epigenetic changes are intimately related to provide a tight control of the ripening process. Recent findings from comparative genomics and system biology approaches are discussed.

\section{Keywords: climacteric fruit, non-climacteric fruit, hormones, ripening, regulation}

Fruits are a distinctive characteristic of Angiosperms. They occur today in a wide variety of forms and types. The ancestral fruit, dry and dehiscent, probably emerged in the early Cretaceous period; fleshy fruits appeared later in the Cretaceous or early Tertiary (Eriksson et al., 2000). The diversification of fruits from a dry dehiscent form to a fleshy drupe or berry, correlated with the rise of vertebrates, main agents of seed dispersal (Knapp, 2002). The maturation of fruits is a complex and highly coordinated developmental process. In fleshy fruits, ripening results in the production of succulent, flavorful, and soft pericarp that attract animals and facilitate seed dispersal (Giovannoni, 2001). In addition to softening, fruits normally exhibit increased accumulation of sugars, acids, pigments, and volatiles that increase interest and palatability to animals. Moreover, fruits are an important source of supplementary diet, providing minerals, vitamins, fibers, and antioxidants for humans. From an agronomical point of view, nutritional value, flavor, processing qualities, and shelf-life determine the quality of fruits.

The main changes associated with ripening include color (loss of green color and increase in non-photosynthetic pigments that vary depending on species and cultivar), firmness (softening by cell wall degrading activities and alterations in cuticle properties), taste (increase in sugar and decline in organic acids), and flavor (production of volatile compounds providing the characteristic aroma).

Analytical tools that allow comprehensive phenotyping at the level of transcriptome (Alba et al., 2005; Vriezen et al., 2008; Matas et al., 2011; Rohrmann et al., 2011), proteome (Lee et al., 2004; Rose et al., 2004; Saravanan and Rose, 2004), and metabolome
(Fait et al., 2008; Lombardo et al., 2011) facilitate an overview of the metabolic network (Carrari et al., 2006; Deluc et al., 2007; Grimplet etal., 2007; Enfissi etal., 2010; Zamboni et al., 2010; Osorio et al., 2011, 2012; Rohrmann et al., 2011; Lee et al., 2012; Pan et al., 2013); whilst network analysis is beginning to yield a detailed understanding of the systems regulation underlying fruit development.

\section{HORMONAL AND TRANSCRIPTIONAL REGULATION DURING RIPENING}

Fruits are generally classified into two physiological groups, climacteric and non-climacteric, according to their respiratory activity and associated ethylene biosynthesis profiles during ripening. Ethylene synthesis in climacteric fruits such as tomato, apple, and banana, is essential for normal fruit ripening and blocking either synthesis or perception of this hormone prevents ripening (Hamilton et al., 1990; Oeller et al., 1991; Rottmann et al., 1991; Barry et al., 1996).

Efforts to uncover the transcriptional regulation underlying carpel and fruit development were first focused on the dry dehiscent siliques of the model plant Arabidopsis (Liljegren et al., 2000; Dinneny etal., 2005). These studies clarified the role of several MADS-box transcription factors in tissue specification and mechanism of dehiscence. Among these, the redundant SHATTERPROOF $1 / 2$ genes (SHP, members of the AGAMOUS subfamily) specified valve margin identity in the silique: when mutated, fruits became indehiscent. However, despite the striking anatomical differences between dry and fleshy fruits, subsequent studies, primarily focused on tomato, have shown the involvement 
in ripening regulation of several orthologs of those MADS-box genes previously characterized in Arabidopsis (Pnueli et al., 1994; Itkin et al., 2009; Vrebalov et al., 2009; Giménez et al., 2010; Bemer et al., 2012). It is now clear that a part of the regulatory networks underlying fruit development have been conserved during the evolution of fleshy fruits (Smaczniak et al., 2012; Seymour et al., 2013).

A number of important advances in our understanding of mechanisms that regulate ripening have also come from the characterization of monogenic tomato mutants, including ripeninginhibitor ( $\mathrm{rin}$ ), non-ripening (nor), colorless non-ripening ( $\mathrm{Cnr}$ ), green-ripe $(G r)$, green flesh $(g f)$, high pigment $1(h p 1)$, high pigment $2(h p 2)$, and never-ripe (Nr; Lanahan et al., 1994; Mustilli et al., 1999; Vrebalov et al., 2002; Liu et al., 2004; Barry and Giovannoni, 2006; Manning et al., 2006; Barry et al., 2008). The rin mutant encodes a partially deleted MADS-box protein of the SEPALLATA clade (SEP4; Hileman et al., 2006), whereas Cnr is an epigenetic change which alters the promoter methylation of SQUAMOSA promoter binding (SPB) protein. NOR is a member of the NAC-domain transcription factor family (Giovannoni, 2007). A recent study in which the transcriptome, proteome, and targeted metabolite analysis were combined during development and ripening of nor and rin mutants, has helped to refine the ethylene-regulated expression of downstream genes and added to our knowledge the role of this hormone in both protein- and metabolite regulation in tomato ripening (Osorio et al., 2011). This data supported the view that nor and rin act together in a cascade to control ripening (Giovannoni et al., 1995; Thompson et al., 1999) and also suggested that nor has a more global effect on ethylene/ripening-related gene expression than rin, which indicates that nor likely operates upstream of rin. Recently, using a combined approach based on chromatin immunoprecipitation and transcriptome analysis, it was provided evidence that RIN interacts with the promoters of more than 200 genes, modulating the expression of its targets by activation or repression. RIN target genes are major regulators of ripening control, such as CNR and NOR, or belong (Martel et al., 2011) to well-known pathways active during the transition from green to ripe fruits (e.g., carotenoid accumulation, chlorophyll breakdown, ethylene synthesis and perception; Fujisawa et al., 2013).

Fruits such as strawberry, citrus, and grape have been classified as non-climacteric, based on the lack of the respiratory burst and on the low endogenous production of ethylene compared to standard climacteric fruits (Perkins-Veazie, 1995). In pepper fruits, some cultivars seem to be ethylene-insensitive, while others pepper cultivars treated with exogenous ethylene were able to stimulate the expression of ripening-specific genes (Armitage, 1989; Ferrarese et al., 1995; Harpster et al., 1997; El-Kereamy et al., 2003).

In strawberry, which has emerged as a prime model of nonclimacteric fruit ripening, ethylene is relatively high in green fruits, decreases in white fruits, and finally increases again at the red stage of ripening (Perkins-Veazie et al., 1996; Iannetta et al., 2006). Interestingly, this last increase is accompanied by an enhanced respiration rate that resembles the one that occurs in climacteric fruits at the onset of ripening (Iannetta et al., 2006). For better understanding the function of ethylene during strawberry ripening, different approaches have been used. External application of ethylene caused the down-regulation of several cell wall-related genes, such as $\beta$-galactosidase, pectin methylesterase, or $\beta$-xylosidase (Trainotti et al., 2001; Castillejo et al., 2004; Bustamante et al., 2009), while the expression of other genes such as expansin, FaEXP2 (Civello et al., 1999) was ethylene-insensitive. Recent studies at transcriptomic and metabolomic levels in transgenic strawberry fruits with decreased ethylene sensitivity indicates that ethylene action is required for normal fruit development, acting differently in the two parts of strawberry fruit, achenes and receptacle (Merchante et al., unpublished data). These results show that, although not as relevant as in climacteric fruits, ethylene may nevertheless play a role in strawberry fruit ripening.

Recent comparative transcriptome and metabolome studies during the maturation processes of climacteric and nonclimacteric fruits (tomato and pepper, respectively) suggest that both species have similar ethylene-mediated signaling components. In pepper, the regulation of these genes is, however, clearly different and may reflect altered ethylene sensitivity or regulators other than ethylene than in tomato (Osorio etal., 2012). Unlike the situation described in tomato the ethylene biosynthesis genes, aminocyclopropane-1-carboxylic acid (ACC) synthase, and ACC oxidase, are not induced in pepper. However, genes downstream of ethylene perception, such as cell wall-related genes, ethylene response factor 3 (ERF3), and carotenoid biosynthesis genes, are up-regulated during pepper fruit ripening (Osorio et al., 2012). Other commonly regulated genes between climacteric and non-climacteric fruits have been described. In strawberry, a SEPALLATA gene (SEP1/2; MADS-box) is needed for normal development and ripening (Seymour et al., 2011). Similarly, in banana, which is classified as a climacteric fruit, the MADS-box SEP3 gene also displays ripening-related expression (Elitzur et al., 2010). In apple, MADS2 gene expression is also associated with fruit firmness (Cevik et al., 2010), whereas in bilberry fruit, the SQUAMOSA MADS-box ortholog of the TDR4 gene in tomato, has a role in regulation of anthocyanin biosynthesis (Jaakola et al., 2010; see Figure 1).

Current knowledge about the role of hormones - other than ethylene - in the development and ripening of climacteric and non-climacteric fruits is limited. In tomato, pepper, banana, muskmelon, and strawberry, the most abundant free auxin, indole-3-acetic acid (IAA), has been reported to decline prior to the onset of ripening; this reduction was accompanied by an increase of its conjugated form (IAA-Asp; Bottcher et al., 2010). The conjugation reaction is catalyzed by the IAA-amino synthase gene (GH3). In tomato, 15 members of GH3 gene family have been described, but only for two of them is the pattern of expression associated with ripening (Kumar et al., 2012). Tomato fruits overexpressing the pepper $G H 3$ gene show anticipation of ripening (Liu et al., 2005), which is in agreement with the view that the ratio between IAA and its AA-conjugated form, rather than the level of IAA itself, may contribute to the temporal regulation of ripening (Bottcher et al., 2010). In non-climacteric fruits, no single growth regulator appears to play a positive role analogous to that played by ethylene, but it has been observed that auxin can negatively control the ripening of some non-climacteric fruits. In strawberry, it has been shown that the expression of many ripening-specific 


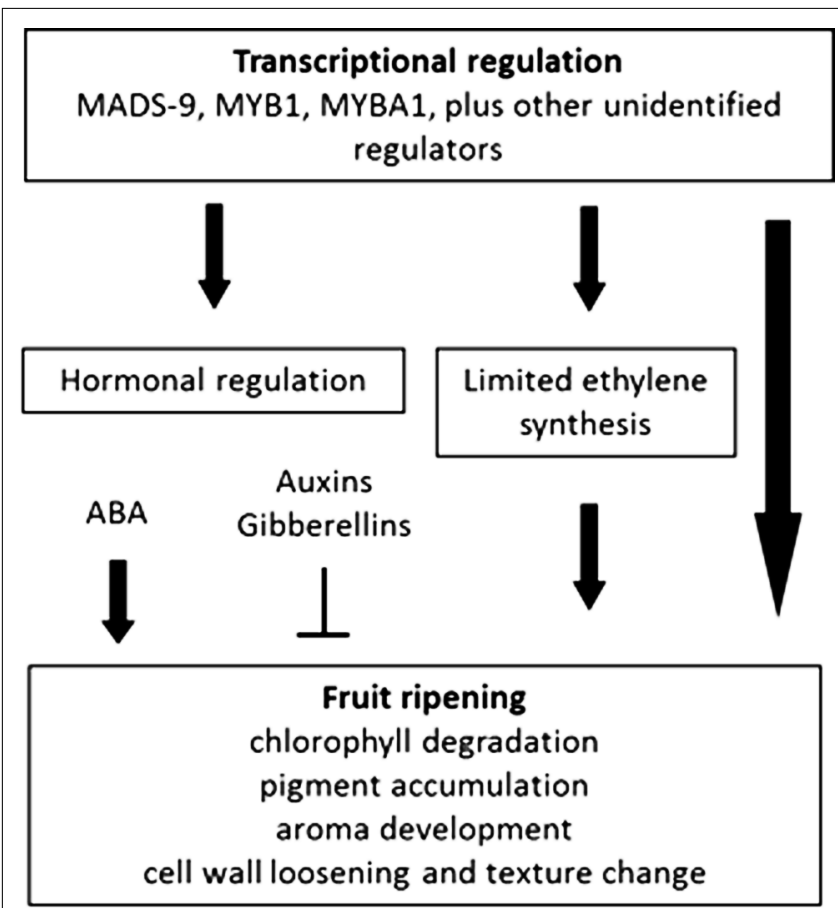

FIGURE 1 | Overview of ripening regulation in non-climacteric fruits.

genes can be down-regulated by treatments with an exogenous auxin. Also in grape auxin seems to play a negative role in the regulation of ripening with synthetic auxin treatments delaying the expression of a number of ripening-related genes (Davies et al., 1997).

As a consequence of the prominent role of auxin in the development and ripening of some non-climacteric fruits, little attention has been paid to possible roles of other plant hormones, such as gibberellins (GAs). However, in strawberry, it has been reported that external application of $\mathrm{GA}_{3}$ to ripening fruits caused a significant delay in the development of the red color (Martinez et al., 1996) and modified the expression of genes involved in cell enlargement (de la Fuente et al., 2006) and cell wall disassembly (Bustamante et al., 2009).

In plants, the phytohormone abscisic acid (ABA) is known to be involved in various aspects of plant growth, development, and responses to environmental stresses (Leung and Giraudat, 1998; Finkelstein and Rock, 2002; Himmelbach et al., 2003; Hirayama and Shinozaki, 2007). ABA promotes sugar accumulation in fleshy fruits (Yamaki and Asakura, 1991; Kobashi et al., 1999; Richings et al., 2000; Pan etal., 2005) and plays a role in the regulation of climacteric and non-climacteric fruit ripening (Coombe, 1992; Davies et al., 1997; Giovannoni, 2001; Rodrigo et al., 2003; Zhang et al., 2009; Sun et al., 2012). In tomato, the suppression of the gene that catalyzes the first step in ABA biosynthesis (NCED1, 9cis-epoxycarotenoid dioxygenase), results in the down-regulation of some ripening-related cell wall genes, such as polygalacturonase and pectinmethylesterase, as well as an increase in firmness and longer shelf-life (Sun et al., 2012). Similarly, reduction of NCED expression correlates with retardation of ripening in strawberry
(Jia et al., 2011). ABA is considered a ripening-inducer in strawberry and grape fruits (Chai et al., 2011; Jia et al., 2011). The mechanisms of ABA signaling is not known, however, in grape, analysis of the GH3 promoter identified ABRE-like elements, which may indicate that the $\mathrm{ABA}$ /auxin content ratio is related to the initiation of ripening (Perkins-Veazie, 1995; Jiang and Joyce, 2003; Bottcher et al., 2010).

In recent years, the level of understanding of the molecular events at the transcriptional, biochemical, hormonal, and metabolite levels underlying ripening in climacteric and non-climacteric fruits has increased considerable (see Figures 1 and 2). However, we still poorly understand the developmental switch that occurs in hormone responsiveness during the transition from immature to ripe fruits. To date, most published studies of transcriptional and metabolic regulation are of relatively low resolution at both spatial and temporal levels and are furthermore restricted in coverage of various cell molecular entities. However, new emerging technologies as well as improved statistical tools (Klie et al., 2011) allow us to further refine our analytical ability in order to cope with issues as subcellular compartmentation and contrasting behavior of different cell types (Caldana et al., 2012). Additionally, the availability of high quality fruit genome sequence data (Jaillon et al., 2007; Shulaev et al., 2011; Tomato Genome Consortium, 2012) will aid our understanding about the genetic regulation of fruit development and ripening.

\section{EPIGENETIC REMODELING DURING RIPENING}

Epigenetic regulation of gene expression (inheritance without an alteration in the primary DNA sequence) is increasingly recognized as mechanism for modulating genome activity. Naturally occurring epigenetic changes at a single gene locus in plants can result in heritable morphological variation without alteration of the underlying DNA sequence (Patterson et al., 1993; Cubas etal., 1999; Manning etal., 2006). DNA methylation is one form of epigenetic regulation. It is involved in transcriptional regulation, stress responses and furthermore plays a major role in protecting the genome integrity against the activity of transposable elements (TEs) and other repetitive sequence (Chan et al., 2005).

In plants, DNA methylation occurs at cytosine residues in three different sequences (CG, $\mathrm{CHG}$, and $\mathrm{CHH}$, where $\mathrm{H}=\mathrm{A}, \mathrm{C}$ or $\mathrm{T}$; Cokus et al., 2008) and is set in place and maintained by different factors (Law and Jacobsen, 2010).

Analysis of epigenetic variation in Arabidopsis revealed that at least one-third of expressed genes are methylated in their coding region, and only $5 \%$ of genes are methylated within promoter regions (Zhang et al., 2006; Vaughn et al., 2007). However, the promoter-methylated genes have a higher degree of tissue-specific expression (Zhang et al., 2006; Zilberman and Henikoff, 2007).

The first survey of the frequency and distribution of cytosine methylation sites in tomato dates back to more than 20 years ago, when it was found that polymorphisms in cytosine methylation between two tomato species were relatively abundant and that methylation patterns were stably inherited, from parents to offspring, segregating in a Mendelian fashion. The presence of tissue-specific methylation patterns and the overall decrease of 


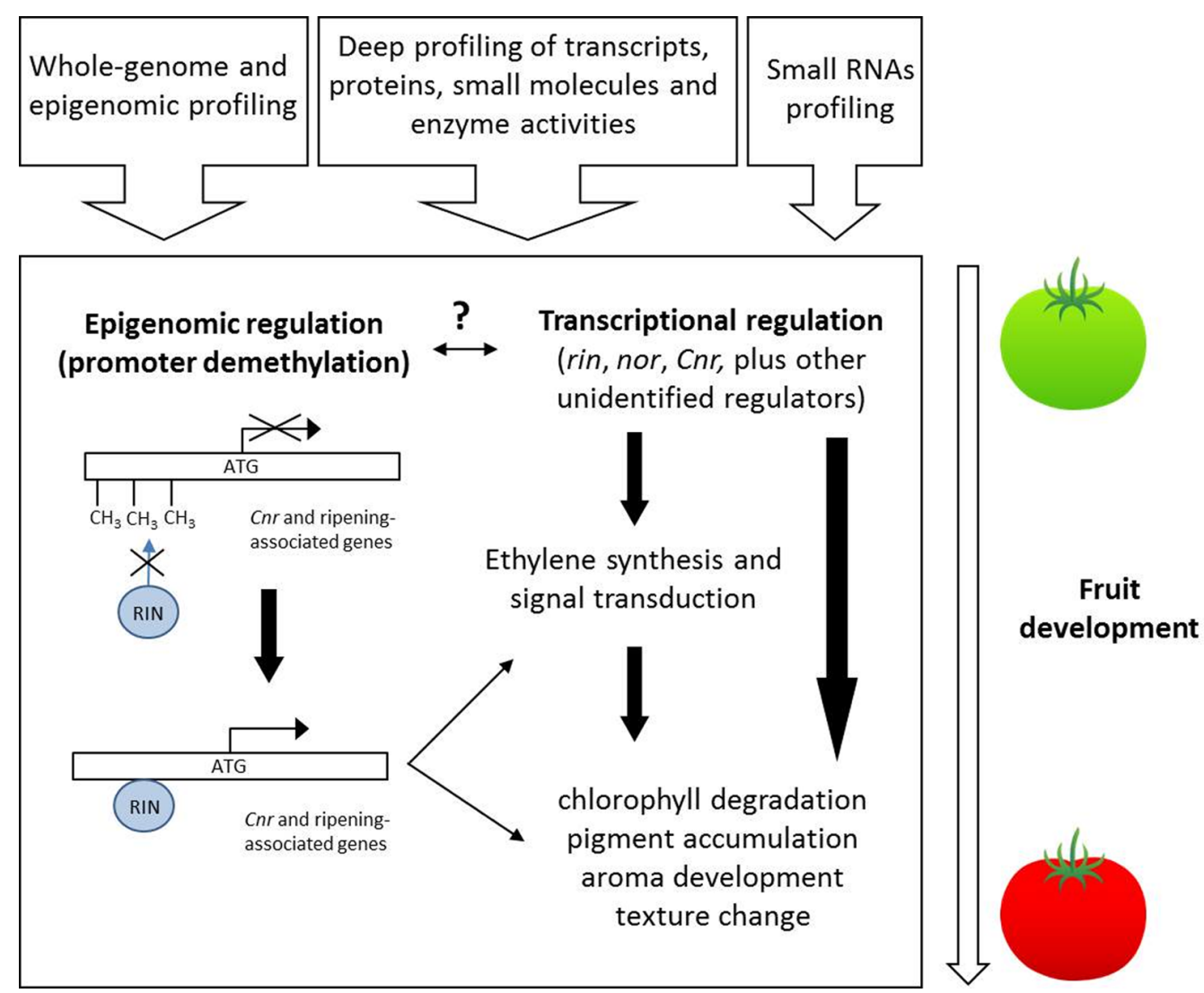

FIGURE 2 | Overview of ripening regulation in climacteric fruits. The contribution of systems profiling approaches (shown at the top) will help identify novel regulatory genes and elucidate the interplay between epigenomic remodeling and transcriptional regulation involved during the ripening process.

5-mC frequency in developing tissues also led the authors to postulate variation of methylation status of selected alleles during plant development (Messeguer et al., 1991).

More recently, the impact of cytosine methylation on tomato fruit ripening has strikingly emerged in the definition of the molecular nature of the colorless non-ripening phenotype. The tomato non-ripening $\mathrm{Cnr}$ mutant fails to produce ripe berries; fruits exhibit green pericarps and do not respond to external applications of ethylene. The gene at the Cnr locus was identified as a SPB protein-like using positional cloning, but the non-ripening phenotype could not be attributed to any alteration in the coding gene sequence. Bisulfite sequencing of the Cnr mutant allele showed instead hypermethylation of cytosine in the region upstream the predicted ATG start site. This hypermethylation state correlated with a drastic reduction of $\mathrm{Cnr}$ gene expression (Manning et al., 2006). Therefore, the non-ripening phenotype was due to the heritable cytosine hypermethylation pattern of the region including the Cnr gene promoter. Additionally, in normal tomato fruit (cv. Liberto) development, the promoter of Cnr appears to be demethylated in a specific region just prior to the onset of ripening. This lead to the hypothesis that DNA methylation contributes to the regulation of fruit ripening (Seymour et al., 2008).

Recent work by Zhong etal. (2013) provides genome-wide insights into the link between the genetic program of fruit ripening and DNA methylation state. On the basis of the previous results on the nature of the $C n r$ (epi) mutation, the authors injected a chemical inhibitor of cytosine methylation, 5-azacytidine, directly in the locular spaces and columella of developing tomato fruits. The methylation inhibitor induced the formation of local ripe areas, red in appearance, where the expression of typical ripeningrelated genes (phytoene synthase 1 and polygalacturonase) was anticipated. Moreover, the $\mathrm{Cnr}$ promoter region was demethylated in red sectors with respect to green parts of the fruits, pointing at the demethylation of $\mathrm{Cnr}$ as the epigenetic signal sufficient to induce ripening. The authors then extended their views on the role of cytosine methylation reporting the full tomato methylome sequences of leaves, immature and ripe fruits, including the ripening-impaired mutants $\mathrm{Cnr}$ and rin. The sequencing of the entire epigenome revealed at least three important results: (i) in wild-type fruits, the degree of methylation of regions upstream the transcription start sites (TSS) decreased gradually along fruit development; (ii) this general decline was not observed for the fruits of the ripening-impaired mutants $\mathrm{Cnr}$ and rin, whose CG methylation levels were constantly higher at TSS and, for Cnr, also comparable to those observed in leaves; (iii) the promoters of typical ripening-related genes were gradually demethylated during development of wild-type fruits. Further evidences about the link between ripening and cytosine methylation came from 
the ChIP-Seq mapping of RIN binding sites during fruit development. The set of RIN targets included 292 genes with a known role in ripening. RIN binding sites were found to be adjacent or overlapping the methylation "hotspots" upstream the TSS. The analysis of methylation status of these regions showed that they were progressively demethylated during the transition from green to red ripe fruits; and this lower level of methylation correlated with higher transcript levels of RIN target genes. A previous study showed that the binding of RIN to a limited set of promoters was inhibited in the Cnr epimutant, indicating that promoter hypermethylation may prevent RIN binding (Martel et al., 2011). These three main findings, i.e., that: (i) local treatment of immature fruits with a DNA demethylating chemical accelerates ripening; (ii) promoters of ripening genes, which contain RIN binding sites, are gradually demethylated during ripening but remain stably hypermethylated in ripening-deficient mutants; (iii) RIN does not bind hypermethylated $\mathrm{Cnr}$ gene promoters (and, possibly, all hypermethylated promoters of its target genes), taken together, assign a key role to the epigenome structure and developmental dynamics in coordinating tomato fruit ripening. The global scenario presented so far also suggests that progressive demethylation of ripening-related gene promoters may be the necessary condition for binding of transcriptional regulators, thus triggering the accumulation of ripening-related transcripts. In normal fruit development, however, the mechanism inducing demethylation

\section{REFERENCES}

Alba, R., Payton, P., Fei, Z. J., McQuinn, R., Debbie, P., Martin, G. B., et al. (2005). Transcriptome and selected metabolite analyses reveal multiple points of ethylene control during tomato fruit development. Plant Cell 17, 2954-2965. doi: 10.1105/tpc.105.036053

Armitage, A. M. (1989). Promotion of fruit ripening of ornamental peppers by ethephon. HortScience 24, 962-964.

Barry, C. S., Blume, B., Bouzayen, M., Cooper, W., Hamilton, A. J., and Grierson, D. (1996). Differential expression of the 1-aminocyclopropane-1-carboxylate oxidase gene family of tomato. Plant J. 9, 525-535. doi: 10.1046/j.1365313X.1996.09040525.x

Barry, C. S., and Giovannoni, J. J. (2006). Ripening in the tomato green-ripe mutant is inhibited by ectopic expression of a protein that disrupts ethylene signaling. Proc. Natl. Acad. Sci. U.S.A. 103, 7923 7928. doi: 10.1073/pnas.0602319103

Barry, C. S., McQuinn, R. P., Chung, M. Y., Besuden, A., and Giovannoni, J. J. (2008). Amino acid substitutions in homologs of the STAY-GREEN protein are responsible for the green-flesh and chlorophyll retainer mutations of tomato and pepper. Plant Physiol. 147, 179-187. doi: $10.1104 /$ pp.108.118430
Bemer, M., Karlova, R., Ballester, A., R., Tikunov, Y., M., Bovy, A., G., WoltersArts, M., et al. (2012). The tomato FRUITFULL homologs TDR4/FUL1 and MBP7/FUL2 regulate ethyleneindependent aspects of fruit ripening. Plant Cell 24, 4437-4451. doi: 10.1105/tpc. 112.103283

Bottcher, C., Keyzers, R. A., Boss, P. K., and Davies, C. (2010). Sequestration of auxin by the indole-3acetic acid-amino synthase GH3-1 in grape berry (Vitis vinifera L.) and the proposed role of auxin conjugation during ripening. J. Exp. Bot. 61, 3615-3625. doi: 10.1093/jxb/erq174

Bustamante, C. A., Civello, P. M., and Martinez, G. A. (2009). Cloning of the promoter region of betaxylosidase (FaXyl1) gene and effect of plant growth regulators on the expression of FaXyll in strawberry fruit. Plant Sci. 177, 49-56. doi: 10.1016/j.plantsci.2009.03.015 and Steinhauser, D. (2012). Unraveling retrograde signaling pathways: finding candidate signaling molecules via metabolomics and systems biology driven approaches. Front. Plant Sci. 3:267. doi: 10.3389/fpls.2012.00267

Carrari, F., Baxter, C., Usadel, B., Urbanczyk-Wochniak, E., Zanor, M. I., Nunes-Nesi, A., et al. (2006). Integrated analysis of metabolite and transcript levels reveals the metabolic
Caldana, C., Fernie, A. R., Willmitzer, L.

of promoters remains elusive, and further efforts are needed in this direction to uncover the "missing link." Given the growing importance of epigenetic modifications in impacting fruit phenotypes, we envisage that, in the future, high-throughput sequencing technologies will allow routine screening of crop epigenomes, accelerating detection of epigenetic variation. We anticipate that screening epigenome structure and dynamics will coexist with the analysis of conventional genetic variation in future plant breeding strategies. Epigenetic-based crop improvement approaches may radically impact fruit quality traits, especially for those traits whose allelic variation has been reduced during domestication or recent intensive breeding pressure. As such future modeling work aimed at integrating epigenomic profiling and small RNA profiling alongside the more frequently used transcript, protein, enzyme, and metabolite profiling (as suggested in Figure 2) will allow far greater understanding of the complex dynamics underlying this tightly regulated biological process.

\section{ACKNOWLEDGMENTS}

This work was supported in part by grants from the Max-PlanckGesellschaft (to Sonia Osorio and Alisdair R. Fernie), and by Ministerio de Ciencia e Innovación, Spain (Ramón and Cajal contract). Federico Scossa acknowledges the support of CRA-Young Investigator Program.

shifts that underlie tomato fruit development and highlight regulatory aspects of metabolic network behavior. Plant Physiol. 142, 1380 1396. doi: 10.1104/pp.106.088534

Castillejo, C., de la Fuente, J. I., Iannetta, P., Botella, M. A., and Valpuesta, V. (2004). Pectin esterase gene family in strawberry fruit: study of FaPE1, a ripening-specific isoform. J. Exp. Bot. 55, 909-918. doi: 10.1093/jxb/erh102 Cevik, V., Ryder, C. D., Popovich, A. Manning, K., King, J. K., and Seymour, G. B. (2010). A FRUITFULLlike gene is associated with genetic variation for fruit flesh firmness in apple (Malus domestica Borkh.). Tree Genet. Genomes 6, 271-279. doi: 10.1007/s11295-009-0247-4

Chai, Y. M., Jia, H. F., Li, C. L., Dong, Q. H., and Shen, Y.Y. (2011). FaPYR1 is involved in strawberry fruit ripening. J. Exp. Bot. 62, 5079-5089. doi: 10.1093/jxb/err207

Chan, S. W., Henderson, I. R., and Jacobsen, S. E. (2005). Gardening the genome: DNA methylation in Arabidopsis thaliana. Genetics 6, 351360. doi: 10.1038/nrg1601

Civello, P. M., Powell, A. L., Sabehat, A., and Bennett, A. B. (1999). An expansin gene expressed in ripening strawberry fruit. Plant Physiol. 121, 1273-1280. doi: 10.1104/ pp.121.4.1273

Cokus, S. J., Feng, S., Zhang, X., Chen, Z., Merriman, B., Haudenschild, C.
D., et al. (2008). Shotgun bisulphite sequencing of the Arabidopsis genome reveals DNA methylation patterning. Nature 452, 215-219. doi: 10.1038 /nature06745

Coombe, B. G. (1992). Research on development and ripening of the grape berry. Am. J. Enol. Vitic. 43, 101-111. doi: 10.1111/j.17550238.2000.tb00171.x

Cubas, P., Vincent, C., and Coen, E. (1999). An epigenetic mutation responsible for natural variation in floral symmetry. Nature 401, 157161. doi: 10.1038/43657

Davies, C., Boss, P. K., and Robinson, S. P. (1997). Treatment of grape berries, a nonclimacteric fruit with a synthetic auxin, retards ripening and alters the expression of developmentally regulated genes. Plant Physiol. 115, 1155-1161.

de la Fuente, J. I., Amaya, I., Castillejo, C., Sanchez-Sevilla, J. F., Quesada, M. A., Botella, M. A., et al. (2006). The strawberry gene FaGAST affects plant growth through inhibition of cell elongation. J. Exp. Bot. 57, 24012411. doi: 10.1093/jxb/erj213

Deluc, L. G., Grimplet, J., Wheatley, M. D., Tillett, R. L., Quilici, D. R., Osborne, C., et al. (2007). Transcriptomic and metabolite analyses of Cabernet Sauvignon grape berry development. BMC Genomics 8:429. doi: 10.1186/1471-21648-429 
Dinneny, J. R., Weigel, D., and Yanofsky, M. F. (2005). A genetic framework for fruit patterning in Arabidopsis thaliana. Development 132, 46874697. doi: 10.1242/dev.02062

Elitzur, T., Vrebalov, J., Giovannoni, J. J., Goldschmidt, E. E., and Friedman, H. (2010). The regulation of MADSbox gene expression during ripening of banana and their regulatory interaction with ethylene. J. Exp. Bot. 61, 1523-1535. doi: 10.1093/jxb/erq017

El-Kereamy, A., Chervin, C., Roustan, J. P., Cheynier, V., Souquet, J. M., Moutounet, M., et al. (2003). Exogenous ethylene stimulates the long-term expression of genes related to anthocyanin biosynthesis in grape berries. Physiol. Plant. 119, 175-182. doi: 10.1034/j.13993054.2003.00165.x

Enfissi, E. M., Barneche, F., Ahmed, I., Lichtle, C., Gerrish, C., McQuinn, R. P., et al. (2010). Integrative transcript and metabolite analysis of nutritionally enhanced DE-ETIOLATED1 downregulated tomato fruit. Plant Cell 22, 1190-1215. doi: 10.1105/ tpc.110.073866

Eriksson, O., Friis, E. M., and Lofgren, P. (2000). Seed size, fruit size, and dispersal systems in angiosperms from the early cretaceous to the late tertiary. Am. Nat. 156, 47-58. doi: $10.1086 / 303367$

Fait, A., Hanhineva, K., Beleggia, R., Dai, N., Rogachev, I., Nikiforova, V. J., et al. (2008). Reconfiguration of the achene and receptacle metabolic networks during strawberry fruit development. Plant Physiol. 148, 730-750. doi: 10.1104/pp.108.120691

Ferrarese, L., Trainotti, L., Moretto, P., deLaureto, P. P., Rascio, N., and Casadoro, G. (1995). Differential ethylene-inducible expression of cellulase in pepper plants. Plant Mol. Biol. 29, 735-747. doi: 10.1007/ BF00041164

Finkelstein, R. R., and Rock, C. D. (2002). Abscisic acid biosynthesis and response. Arabidopsis Book 1:e0058. doi: 10.1199/tab.0058

Fujisawa, M., Nakano, T., Shima, Y., and Ito, Y. (2013). A large-scale identification of direct targets of the tomato MADS Box transcription factor RIPENING INHIBITOR reveals the regulation of fruit ripening. Plant Cell 25, 371-386. doi: 10.1105/tpc. 112.108118

Giménez, E., Pineda, B., Capel, J., Anton, M. T., Atares, A., PerezMartin, F., et al. (2010). Functional analysis of the Arlequin mutant corroborates the essential role of the Arlequin/TAGLl gene during reproductive development of tomato. PLoS
ONE 5:e14427. doi: 10.1371/journal.pone.0014427

Giovannoni, J. (2001). Molecular biology of fruit maturation and ripening. Annu. Rev. Plant Physiol. Plant Mol. Biol. 52, 725-749. doi: 10.1146 annurev.arplant.52.1.725

Giovannoni, J. J. (2007). Fruit ripening mutants yield insights into ripening control. Curr. Opin. Plant Biol. 10, 283-289. doi: 10.1016/ j.pbi.2007.04.008

Giovannoni, J. J., Noensie, E. N., Ruezinsky, D. M., Lu, X., Tracy, S. L., Ganal, M. W., et al. (1995). Molecular genetic analysis of the ripeninginhibitor and non-ripening loci of tomato: a first step in genetic mapbased cloning of fruit ripening genes. Mol. Gen. Genet. 248, 195-206. doi: 10.1007/BF02190801

Grimplet, J., Deluc, L. G., Tillett, R. L., Wheatley, M. D., Schlauch, K. A. Cramer, G. R., et al. (2007). Tissuespecific mRNA expression profiling in grape berry tissues. BMC Genomics 8:187. doi: 10.1186/1471-21648-187

Hamilton, A. J., Lycett, G. W., and Grierson, D. (1990). Antisense gene that inhibits synthesis of the hormone ethylene in transgenic plants. Nature 346, 284-287. doi: 10.1038/346284a0 Harpster, M. H., Lee, K. Y., and Dunsmuir, P. (1997). Isolation and characterization of a gene encoding endo-beta-1,4-glucanase from pepper (Capsicum annuum L) Plant Mol. Biol. 33, 47-59. doi: 10.1023/A:1005795028489

Hileman, L. C., Sundstrom, J. F., Litt, A., Chen, M., Shumba, T., and Irish, V. F. (2006). Molecular and phylogenetic analyses of the MADS-box gene family in tomato. Mol. Biol. Evol. 23, 2245-2258. doi: $10.1093 / \mathrm{mol}-$ bev/msl095

Himmelbach, A., Yang, Y., and Grill, E. (2003). Relay and control of abscisic acid signaling. Curr. Opin. Plant Biol. 6, 470-479. doi: 10.1016/S13695266(03)00090-6

Hirayama, T., and Shinozaki, K. (2007). Perception and transduction of abscisic acid signals: keys to the function of the versatile plant hormone ABA. Trends Plant Sci. 12, 343-351. doi: 10.1016/j.tplants.2007.06.013

Iannetta, P. P. M., Laarhovenb, L. J., Medina-Escobar, N., James, E. K., McManuse, M. T., Davies, H. V., et al. (2006). Ethylene and carbon dioxide production by developing strawberries show a correlative pattern that is indicative of ripening climacteric fruit. Physiol. Plant. 127, 247-259. doi: 10.1111/j.13993054.2006.00656.x
Itkin, M., Seybold, H., Breitel, D. Rogachev, I., Meir, S., and Aharoni, A. (2009). TOMATO AGAMOUS LIKE 1 is a component of the fruit ripening regulatory network. Plant J. 60, 1081-1095. doi: 10.1111/j.1365 313X.2009.04064.X

Jaakola, L., Poole, M., Jones, M. O., Kämäräinen-Karppinen, T., Koskimäki, J. J., Hohtola, A., et al. (2010). A SQUAMOSA MADS box gene involved in the regulation of anthocyanin accumulation in bilberry fruits. Plant Physiol. 153, 16191629. doi: 10.1104/pp.110.158279

Jaillon, O., Aury, J. M., Noel, B., Policriti, A., Clepet, C. Casagrande, A., et al. (2007). The grapevine genome sequence suggest ancestral hexaploidization in major angiosperm phyla. Nature 449, 463465. doi: 10.1038/nature06148

Jia, H. F., Chai, Y. M., Li, C. L., Lu, D., Luo, J. J., Qin, L., et al. (2011) Abscisic acid plays an important role in the regulation of strawberry fruit ripening. Plant Physiol. 157, 188-199. doi: 10.1104/pp.111.177311

Jiang, Y. M., and Joyce, D. C. (2003). ABA effects on ethylene production PAL activity, anthocyanin and phenolic contents of strawberry fruit. Plant Growth Regul. 39, 171-174. doi: 10.1023/A:1022539901044

Klie, S., Krueger, S., Krall, L., Giavalisco, P., Flügge, U. I., Willmitzer, L., et al. (2011). Analysis of the compartmentalized metabolome - a validation of the non-aqueous fractionation technique. Front. Plant Sci. 2:55. doi: 10.3389/fpls.2011.00055

Knapp, S. (2002). Tobacco to tomatoes: a phylogenetic perspective on fruit diversity in the Solanaceae. J. Exp. Bot. 53, 2001-2011. doi: 10.1093/jxb/erf068

Kobashi, K., Gemma, H., and Iwahori, S. (1999). Sugar accumulation in peach fruit as affected by abscisic acid treatment in relation to some sugar metabolizing enzymes. J. Jpn. Soc. Hortic. Sci. 68, 465-470. doi: 10.2503/jjshs.68.465

Kumar, R., Agarwal, P., Tyagi, A. K., and Sharma, A. K. (2012). Genome-wide investigation and expression analysis suggest diverse roles of auxin responsive GH3 genes during development and response to different stimuli in tomato (Solanum lycopersicum). Mol. Genet. Genomics 287, 221-235. doi: 10.1007/s00438-011 0672-6

Lanahan, M. B., Yen, H. C., Giovannoni, J. J., and Klee, H. J. (1994). The never ripe mutation blocks ethylene perception in tomato. Plant Cell 6 521-530. doi: 10.1105/tpc.6.4.521
Law, J. A., and Jacobsen, S. E. (2010). Establishing, maintaining and modifying DNA methylation patterns in plants and animals. Nature 11, 204220. doi: $10.1038 / \mathrm{nrg} 2719$

Lee, J. M., Joung, J. G., McQuinn, R., Chung, M. Y., Fei, Z., Tieman, D., etal. (2012). Combined transcriptome, genetic diversity and metabolite profiling in tomato fruit reveals that the ethylene response factor SIERF6 plays and important role in ripening and carotenoid accumulation. Plant J. 70, 191-204. doi: 10.1111/j.1365-313X.2011.04863.x

Lee, S. J., Saravanan, R. S., Damasceno, C. M. B., Yamane, H., Kim, B. D., and Rose, J. K. C. (2004). Digging deeper into the plant cell wall proteome. Plant Physiol. Biochem. 42, 979-988. doi: 10.1016/j.plaphy.2004.10.014

Leung, J., and Giraudat, J. (1998). Abscisic acid signal transduction. Annu. Rev. Plant Physiol. Plant Mol. Biol. 49, 199-222. doi: 10.1146/ annurev.arplant.49.1.199

Liljegren, S. J., Ditta, G. S., Eshed, Y., Savidge, B., Bowman, J. L., and Yanofsky, M. F. (2000). SHATTERPROOF MADS-box genes control seed dispersal in Arabidopsis. Nature 404, 766-770. doi: 10.1038/35008089

Liu, K., Kang, B. C., Jiang, H., Moore, S. L., Li, H., Watkins, C. B., et al. (2005). A GH3-like gene, $\mathrm{CcGH} 3$, isolated from Capsicum chinense $\mathrm{L}$. fruit is regulated by auxin and ethylene. Plant Mol. Biol. 58, 447-464. doi: 10.1007/s11103-005-6505-4

Liu, Y., Roof, S., Ye, Z., Barry, C., van Tuinen, A., Vrebalov, J., et al. (2004). Manipulation of light signal transduction as a means of modifying fruit nutritional quality in tomato. Proc. Natl. Acad. Sci. U.S.A. 101, 98979902. doi: 10.1073/pnas.0400935101

Lombardo, V. A., Osorio, S., Borsani, J., Lauxmann, M. A., Bustamante, C. A., Budde, C. O., et al. (2011). Metabolic profiling during peach fruit development and ripening reveals the metabolic networks that underpin each developmental stage. Plant Physiol. 157, 1696-1710. doi: 10.1104/pp.111.186064

Manning, K., Tor, M., Poole, M., Hong, Y., Thompson, A. J., King, G. J., et al. (2006). A naturally occurring epigenetic mutation in a gene encoding an SBP-box transcription factor inhibits tomato fruit ripening. Nat. Genet. 38, 948-952. doi: 10.1038/ng1841

Martel, C., Vrebalov, J., Tafelmeyer, P., and Giovannoni, J. J. (2011). The tomato MADS-box transcription factor RIPENING INHIBITOR interacts with promoters involved in numerous 
ripening processes in a COLORLESS NONRIPENING-dependent manner. Plant Physiol. 157, 1568-1579. doi: 10.1104/pp.111.181107

Martinez, G. A., Chaves, A. R., and Anon, M. C. (1996). Effect of exogenous application of gibberellic acid on color change and phenylalanine ammonia-lyase, chlorophyllase, and peroxidase activities during ripening of strawberry fruit (Fragaria $\times$ ananassa Duch). J. Plant Growth Regul. 15, 139-146. doi: 10.1007/BF00198929

Matas, A. J., Yeats, T. H., Buda, G. J., Zheng, Y., Chatterjee, S., Tohge, T., et al. (2011). Tissue- and celltype specific transcriptome profiling of expanding tomato fruit provides insights into metabolic and regulatory specialization and cuticle formation. Plant Cell 23, 3893-3910. doi: 10.1105/tpc.111.091173

Messeguer, R., Ganal, M. W., Steffens, J. C., and Tanksley, S. D. (1991). Characterization of the level, target sites and inheritance of cytosine methylation in tomato nuclear DNA. Plant Mol. Biol. 16, 753-770. doi: 10.1007/BF00015069

Mustilli, A. C., Fenzi, F., Ciliento, R., Alfano, F., and Bowler, C. (1999). Phenotype of the tomato high pigment- 2 mutant is caused by a mutation in the tomato homolog of DEETIOLATED1. Plant Cell 11, 145-157. doi: 10.1105/tpc.11.2.145

Oeller, P. W., Wong, L. M., Taylor, L. P., Pike, D. A., and Theologis, A. (1991). Reversible inhibition of tomato fruit senescence by antisense RNA. Science 254, 437-439. doi: $10.1126 /$ science. 1925603

Osorio, S., Alba, R., Damasceno, C. M. B., Lopez-Casado, G., Lohse, M., Zanor, M. I., et al. (2011). Systems biology of tomato fruit development: combined transcript, protein and metabolite analysis of tomato transcription factor (nor, rin) and ethylene receptor $(\mathrm{Nr})$ mutants reveals novel regulatory interactions. Plant Physiol. 157, 405-425. doi: 10.1104/pp.111.175463

Osorio, S., Alba, R., Nikoloski, Z., Kochevenko, A., Fernie, A. R., and Giovannoni, J. J. (2012). Integrative comparative analyses of transcript and metabolite profiles from pepper and tomato ripening and development stages uncovers species-specific patterns of network regulatory behavior. Plant Physiol. 159, 1713-1729. doi: 10.1104/pp.112.199711

Pan, Q. H., Li, M. J., Peng, C. C., Zhang, N., Zou, X., Zou, K. Q., et al. (2005). Abscisic acid activates acid invertases in developing grape berry. Physiol. Plant. 125, 157-170. doi: 10.1111/j.1399-3054.2005.00552.x

Pan, Y., Bradley, G., Pyke, K., Ball, G. Lu, C., Fray, R., et al. (2013). Network inference analysis identifies an APRR2-like gene linked to pigment accumulation in tomato and pepper fruits. Plant Physiol. 161, 1476-1485. doi: 10.1104/pp.112.212654

Patterson, G. I., Thorpe, C. J., and Chandler, V. L. (1993). Paramutation, an allelic interaction, is associated with a stable and heritable reduction of transcription of the maize b regulatory gene. Genetics 135, 881-894.

Perkins-Veazie, P. M. (1995). Growth and ripening of strawberry fruit. Hortic. Rev. 17, 267-297. doi: 10.1002/9780470650585.ch8

Perkins-Veazie, P. M., Huber, D. J., and Brecht, J. K. (1996). In vitro growth and ripening of strawberry fruit in presence of ACC, STS or propylene. Ann. Appl. Biol. 128, 105-116. doi: 10.1111/j.1744-7348.1996.tb07094.x

Pnueli, L., Hareven, D., Rounsley, S., D., Yanofsky, M., F., and Lifschitz, E. (1994). Isolation of the tomato AGAMOUS gene TAG1 and analysis of its homeotic role in transgenic plants. Plant Cell 6, 163-173. doi: 10.1105/tpc.6.2.163

Richings, E. W., Cripps, R. F., and Cowan, A. K. (2000). Factors affecting 'Hass' avocado fruit size: carbohydrate, abscisic acid and isoprenoid metabolism in normal and phenotypically small fruit. Physiol. Plant. 109, 81-89. doi: 10.1034/j.13993054.2000.100112.x

Rodrigo, M. J., Marcos, J. F., Alferez, F., Mallent, M. D., and Zacarias, L. (2003). Characterization of Pinalate, a novel Citrus sinensis mutant with a fruit-specific alteration that results in yellow pigmentation and decreased ABA content. J. Exp. Bot. 54, 727-738. doi: $10.1093 /$ jxb/erg083

Rohrmann, J., Tohge, T., Alba, R. Osorio, S., Caldana, C., McQuinn, R., etal. (2011). Combined transcription factor profiling, microarray analysis and metabolite profiling reveals the transcriptional control of metabolic shifts occurring during tomato fruit development. Plant J. 68, 999-1013. doi: 10.1111/j.1365313X.2011.04750.x

Rose, J. K. C., Bashir, S., Giovannoni, J. J., Jahn, M. M., and Saravanan, R. S. (2004). Tackling the plant proteome: practical approaches, hurdles and experimental tools. Plant J. 39, 715-733. doi: 10.1111/j.1365313X.2004.02182.x

Rottmann, W. H., Peter, G. F., Oeller P. W., Keller, J. A., Shen, N.
F., Nagy, B. P., et al. (1991). 1 Aminocyclopropane-1-carboxylate synthase in tomato is encoded by a multigene family whose transcription is induced during fruit and floral senescence. J. Mol. Biol. 222, 937961. doi: 10.1016/0022-2836(91) 90587-V

Saravanan, R. S., and Rose, J. K. C. (2004). A critical evaluation of sample extraction techniques for enhanced proteomic analysis of recalcitrant plant tissues. Proteomics 4, 2522-2532. doi: 10.1002/pmic. 200300789

Seymour, G., Poole, M., Manning, K., and King, G. J. (2008). Genetics and epigenetics of fruit development and ripening. Curr. Opin. Plant Biol. 11, 58-63. doi: 10.1016/j.pbi.2007.09.003

Seymour, G. B., Ostergaard, L., Chapman, N. H., Knapp, S., and Martin, C. (2013). Fruit development and ripening. Annu. Rev. Plant Biol. 64, 219-241. doi: 10.1146/annurevarplant-050312-120057

Seymour, G. B., Ryder, C. D., Cevik, V., Hammond, J. P., Popovich, A. King, G. J., et al. (2011). A SEPALLATA gene is involved in the development and ripening of strawberry (Fragaria $\times$ ananassa Duch.) fruit, a non-climacteric tissue. J. Exp. Bot. 62, 1179-1188. doi: 10.1093/jxb/erq360

Shulaev, V., Sargent, D. J., Crowhurst, R. N., Mockler, T. C., Folkerts, O., Delcher, A. L., et al. (2011). The genome of woodland strawberry (Fragaria vesca). Nat. Genet. 43, 109-116. doi: 10.1038/ng.740

Smaczniak, C., Immink, R. G. Angenent, G. C., and Kaufmann, K. (2012). Developmental and evolutionary diversity of plant MADSdomain factors: insights from recent studies. Development 139, 30813098. doi: 10.1242/dev.074674

Sun, L., Sun, Y., Zhang, M., Wang, L., Ren, J., Cui, M., et al. (2012). Suppression of 9-cis-epoxycarotenoid dioxygenase, which encodes a key enzyme in abscisic acid biosynthesis, alters fruit texture in transgenic tomato. Plant Physiol. 158, 283, 298. doi: 10.1104/pp.111.186866

Thompson, A. J., Tor, M., Barry, C. S., Vrebalov, J., Orfila, C., Jarvis, M. C., et al. (1999). Molecular and genetic characterization of a novel pleiotropic tomato-ripening mutant Plant Physiol. 120, 383-390. doi: 10.1104/pp.120.2.383

Tomato Genome Consortium. (2012). The tomato genome sequence provides insights into fleshy fruit evolution. Nature 485, 635-641. doi: 10.1038/nature11119
Trainotti, L., Spinello, R., Piovan, A., Spolaore, S., and Casadoro, G. (2001). beta-Galactosidases with a lectin-like domain are expressed in strawberry. J. Exp. Bot. 52, 16351645. doi: 10.1093/jexbot/52.361. 1635

Vaughn, M. W., Tanurdzic, M., Lippman, Z., Jiang, H., Carrasquillo, R., Rabinowicz, P. D., et al. (2007). Epigenetic natural variation in Arabidopsis thaliana. PLoS Biol. 5:e174. doi: 10.1371/journal.pbio.0050174

Vrebalov, J., Pan, I., L., Arroyo, A., J., McQuinn, R., Chung, M., Poole, M., et al. (2009). Fleshy fruit expansion and ripening are regulated by the Tomato SHATTERPROOF gene TAGL1. Plant Cell 21, 3041-3062. doi: 10.1105/tpc.109.066936

Vrebalov, J., Ruezinsky, D., Padmanabhan, V., White, R., Medrano, D., Drake, R., et al. (2002). A MADS-box gene necessary for fruit ripening at the tomato ripening-inhibitor (rin) locus. Science 296, 343-346. doi: 10.1126/science. 1068181

Vriezen, W. H., Feron, R., Maretto, F., Keijman, J., and Mariani, C. (2008). Changes in tomato ovary transcriptome demonstrate complex hormonal regulation of fruit set. New Phytol. 177, 60-76. doi:10.1111/j. 1469-8137.2007.02254.x

Yamaki, S., and Asakura, T. (1991). Stimulation of the uptake of sorbitol into vacuoles from apple fruit flesh by abscisic acid and into protoplasts by indoleacetic acid. Plant Cell Physiol. 32, 315-318.

Zamboni, A., Di Carli, M., Guzzo, F., Stocchero, M., Zenoni, S., Ferrarini, A., et al. (2010). Identification of putative stage-specific grapevine berry biomarkers and omics data integration into networks. Plant Physiol. 154, 1439-1459. doi: 10.1104/pp.110.160275

Zhang, M., Leng, P., Zhang, G., and Li, X. (2009). Cloning and functional analysis of 9-cis-epoxycarotenoid dioxygenase (NCED) genes encoding a key enzyme during abscisic acid biosynthesis from peach and grape fruits. J. Plant Physiol. 166, 1241-1252. doi: 10.1016/j.jplph. 2009.01.013

Zhang, X., Yazaki, J., Sundaresan, A., Cokus, S., Chan, S. W., Chen, H., et al. (2006). Genome-wide highresolution mapping and functional analysis of DNA methylation in Arabidopsis. Cell 126, 1189-1201. doi: 10.1016/j.cell.2006.08.003

Zhong, S., Fei, Z., Chen, Y. R., Zheng, Y., Huang, M., Vrebalov, J., et al. (2013). Single-base resolution methylomes of tomato fruit development reveal 
epigenome modifications associated with ripening. Nat. Biotechnol. 31, 154-159. doi: 10.1038/nbt. 2462

Zilberman, D., and Henikoff, S. (2007). Genome-wide analysis of DNA methylation patterns. Development 134, 3959-3965. doi: $10.1242 / \mathrm{dev}$. 001131
Conflict of Interest Statement: The authors declare that the research was conducted in the absence of any commercial or financial relationships that could be construed as a potential conflict of interest.

Received: 06 March 2013; paper pending published: 23 April 2013; accepted:
28 May 2013; published online: 14 June 2013.

Citation: Osorio S, Scossa F and Fernie AR (2013) Molecular regulation of fruit ripening. Front. Plant Sci. 4:198. doi: 10.3389/fpls.2013.00198

This article was submitted to Frontier in Plant Systems Biology, a specialty of Frontiers in Plant Science.
Copyright () 2013 Osorio, Scossa and Fernie. This is an open-access article distributed under the terms of the Creative Commons Attribution License, which permits use, distribution and reproduction in other forums, provided the original authors and source are credited and subject to any copyright notices concerning any third-party graphics etc. 